Rev. Latinoam. Psicopat. Fund., São Paulo, v. 14, n. 2, p. 390-395, junho 2011

O eu em ruína. Perda e falência psíquica

Eliane Michelini Marraccini (Org.)

São Paulo: Primavera Editorial, 2010

\title{
O eu em ruína. Perda e falência psíquica
}

Ernesto René Sang

Freud comparou o trabalho do psicanalista ao trabalho do arqueólogo que, a partir de alguns vestígios e restos materiais, procura montar o que pode ter pertencido a uma civilização. De forma análoga, o psicanalista procuraria encontrar formas simbólicas - a partir dos restos de memórias diretamente como lembranças infantis, ou indiretamente, por meio das formações oníricas, sintomas, atos falhos na linguagem e vivências sensoriais - que permitam à consciência impregnar de sentidos cognoscíveis o eu.

O "Eu em ruína" é uma coletânea que instiga a leitura crítica. Desafia as teorias que orientam a nossa capacidade de observação clínica. Os autores nos brindam em seus artigos com a árdua tarefa de colocar as teorias psicanalíticas a trabalhar. De Freud a Klein, Winnicott e Bion, aos psicanalistas-autores mais contemporâneos como Green, Lacan, Fédida, Aulagnier. Procuram desvendar a brecha que possibilita encontrar um pouco de vida no eu em ruínas.

Assim, o título da coletânea de trabalhos reunidos por Eliane Michelini Marraccini sob o tema "O Eu em ruína", su- 
gere em primeira mão relatos de excursões arqueológicas em sobreviventes de uma catástrofe. Hoje as catástrofes mais comuns se caracterizam pelo excesso: da fumaça expelida pelos vulcões que impedem as viagens aéreas intercontinentais, do movimento violento de uma massa extraordinária dos oceanos como tsunamis que avançam sobre a terra, assim como por um excesso de expectativa na maneira de viver a contemporaneidade, tornando-se quase um dever ser feliz no mundo de hoje. Paradoxalmente, as ruínas que hoje admiramos dos templos da Antiga Grécia e do Império Romano são sobreviventes de cataclismas acontecidos e, dessa forma, permitem reconstruir o espaço de vida dessas civilizações. Os trabalhos da coletânea nos trazem o esforço de psicanalistas para enfrentar e resgatar o eu que sobreviveu à perda, que chegou em estado de falência psíquica à sala de análise.

A coletânea nos propõe pensar se o exame metapsicológico que os diversos autores realizam configura de fato a noção do "Eu em ruínas" como um conceito que articula fatos clínicos em uma nova teoria do Eu.

Laplanche e Pontalis (1974) no verbete sobre o Ego (Eu) nos lembram que a teoria psicanalítica tenta explicar a gênese do ego dentro de dois registros relativamente heterogêneos, seja considerando-o como um aparelho adaptativo di-

ferenciado a partir do id em virtude do contato com a realidade exterior, seja definindo-o como o resultado de identificações que conduzem à formação, dentro da pessoa, de um objeto de amor investido pelo id. Estamos falando da formação do ego que resulta da identificação com os relacionamentos primordiais do bebê com a mãe, de um psiquismo inicial de um sujeito incipiente, com seus objetos primitivos de amor e ódio enquanto experiências emocionais estruturantes. Penso tratar-se de uma estrutura do Eu formada basicamente no movimento de introjeção e projeção das fantasias inconscientes relativas aos objetos primordiais, que vão se constituindo em objetos internalizados, e que, dessa maneira, constroem o ego como uma estrutura relacional movida pelas pulsões.

A própria organizadora da coletânea reconhece que a noção "eu em ruína" abriga uma complexidade intrínseca. "Diz respeito a uma falha na constituição psíquica e envolve um comprometimento da coluna de sustentação do eu, edificada em torno do eixo de estruturação narcísica e do fortalecimento egoico, alicerces centrais da subjetividade" (Marraccini, p. 30).

\section{O que é, então, o "Eu em ruínas”?}

O "eu em ruína” é a expressão da subjetividade de pessoas com dificuldade em processar o necessário luto, permanecendo impossibilitados de reorgani- 
zação subjetiva após vivência traumática, submersos em sua dor e perdidos no vazio de si mesmos. Quando o ego se encontra numa situação de excessivo perigo real, que acredita ser incapaz de superar com suas próprias forças (...) sente-se abandonado por todas as forças protetoras e deixa-se morrer. Isto pode acontecer como resposta à experiência traumática da perda de um ser amado, de seu amor, ou de algo que tenha ocupado esse lugar, o que leva o eu a sucumbir ao colapso, de forma dramática e, por vezes, integral. O Eu perde bases importante de sustentação emocional. Sobrevive sem razão de existir como se o ser amado tivesse levado consigo sua alma.

Como nos lembra a organizadora, "Tem lugar em um psiquismo que, embora de funcionamento primitivo, mantinha-se razoavelmente edificado antes da comoção transbordante dessa perda. Uma perda real, mas que, no entanto, constitui também uma perda imaginária e representa simbolicamente uma perda essencial para o psiquismo" (p. 30).

\section{O “Eu em ruínas” nos propõe uma discussão sobre a noção de narcisismo}

Freud (1914) se pergunta o que acontece com o amor desmesurado por si mesmo que caracteriza o narcisismo primário da criança quando, depois de adulta, se depara com as frustrações do mundo exterior. Pensa que o ser humano não pode dispensar o desejo de perfeição narcísico de sua infância: este não desaparece, mas é substituído pela constituição de uma instância intrapsíquica, que ele chama tanto de ego ideal como de ideal do ego. Ou seja, aquilo que o adulto projeta diante dele como seu ideal nada mais é que o "substituto do narcisismo perdido de sua infância; nessa época, ele era seu próprio ideal” (p. 98). Mas a formação de um ideal com o qual o indivíduo está sempre medindo seus pensamentos e suas ações produz um aumento das exigências em relação ao ego, papel que é desempenhado pela consciência moral como Freud presume.

A coletânea em questão mostra claramente que, atualmente, existe uma grande diversidade na maneira com que os psicanalistas concebem o narcisismo, seja do ponto de vista teórico ou técnico, de maneira que a abordagem terapêutica varia em consequência disso. Para ordenar essa variedade, ao menos didaticamente, Quinodoz (2007) aponta duas grandes tendências terapêuticas entre os psicanalistas em função da concepção de narcisismo que adotam. Esses modelos diferentes dão lugar a abordagens técnicas diferentes no tratamento psicanalítico dos distúrbios narcísicos.

De um lado, encontram-se psicanalistas que seguem Freud em sua concepção do narcisismo primário, pensam que existe no início da vida uma fase em que 
a criança ainda não conhece o objeto: trata-se para eles de uma fase normal do desenvolvimento infantil. D. W. Winnicott é um dos psicanalistas que adere à ideia de que a identificação primária reina no início da vida, ainda que não utilize a expressão narcisismo primário. Afirma que a criança acredita que forma uma unidade com sua mãe e que sua mãe forma uma unidade com ela. Nessa fase, o bebê tem a ilusão de que criou seu objeto, e a função da mãe é manter essa ilusão até que a criança seja capaz de renunciar a ela. Em caso de evolução desfavorável, observam-se distúrbios do "desenvolvimento emocional primitivo". Assim, nesses pacientes, a meta da cura psicanalítica consiste em permitir que regridam a uma fase de dependência infantil precoce, em que o analisando e o setting se fundem em um narcisismo primário a partir do qual o "verdadeiro self" poderá se desenvolver.

De outro lado, estão os psicanalistas que consideram que desde o início da vida se estabelece uma relação de objeto, e nisso seguem M. Klein; para estes, não existe na criança uma fase narcísica primordial no sentido em que Freud entendia, mas apenas "fases narcísicas". Sustentam que o ego do recém-nascido percebe imediatamente o objeto de maneira que os fenômenos narcísicos são considerados como expressão de pulsões libidinais e agressivas, e que defesas são erigidas no momento em que o objeto é percebido como separado e diferente de si. Sendo assim, a interpretação das angústias de diferenciação e de separação que surgem na relação com o analista são extremamente importantes. Para H. Rosenfeld, analista kleiniano, o narcisismo se baseia na onipotência e na idealização do self obtidas por meio da identificação introjetiva e projetiva com o objeto idealizado. Essa identificação com o objeto idealizado levou a negar a diferença e a fronteira entre o eu e o objeto. A inveja tem igualmente um papel essencial nos fenômenos narcísicos. Segundo Rosenfeld, qualquer que seja a força das pulsões destrutivas, é essencial na clínica encontrar um acesso à parte libidinal dependente, de maneira a atenuar a influência do ódio e da inveja e, assim, permitir ao paciente estabelecer boas relações de objeto. Numa posição muito próxima do Rosenfeld, H. Segal considera que o conceito de pulsão de vida e de morte pode ajudar a resolver o problema da hipótese freudiana do narcisismo primário. Para ela, o narcisismo pode assumir a forma de idealização da morte e de um ódio da vida em que alguns pacientes, com o risco de provocar neles o desejo de aniquilar não apenas o objeto, mas também o próprio self, desejo este que surge como uma defesa contra a percepção do objeto. Para esta autora, é na relação transferencial que pode permitir a emergência da depressividade, uma capacidade depressiva criativa que anteriormente não conseguiu ser alcançada. 


\section{Sobre a origem do "Eu em ruína" e perspectivas terapêuticas}

Os autores, cada um à sua maneira, estilo e preferência teórica, procuram dar acolhimento ao sofrimento do "Eu em ruína", gerar hipóteses sobre a gênese dessa estrutura egoica precária e esboçar o projeto terapêutico desejado e adequado a cada um desses "Eus em ruína": atualizando crenças inconscientes, confrontando-as no setting analítico, interpretando-as, permitindo que o Eu consciente confronte o superego arcaico.

Uma ideia comum nos diversos trabalhos apresentados refere-se ao vazio existencial que constitui a vivência subjetiva da ruína. Vazio existencial como registro psíquico resultante da falha do objeto primário (mãe) em captar e reconhecer seu bebê como sendo um outro ser com existência própria através de refletir e significar o que ele vive. O projeto terapêutico consistirá em oferecer aquilo que não foi dado, como se destaca na perspectiva winnicottiana.

O sofrimento que acompanha o "Eu em ruína" exige a confiança na segurança oferecida pelo analista e seu setting para que se processe o compartilhamento dessa experiência que humaniza. Por quê? Na perspectiva kleiniana a angústia predominante é pela sobrevivência do ego, resultado da ação da pulsão de morte que o submete à influência impiedosa do superego arcaico e dos ideais que ele contém. Dessa maneira, é impedido o reconhecimento do objeto como separado do ego, em relação ao qual é sentido tanto ódio quanto amor, já que na vivência da angústia pela sobrevivência do ego, este se apega ao objeto parcial idealizado que lhe garante segurança de sobreviver. Na melancolia, o superego se torna uma espécie de concentração da pulsão de morte.

Cintra (2010) nos lembra que a ruína do eu surge quando o vínculo com o objeto se mostra, por um lado, intenso graças à idealização (e desidealização), pela invenção do outro de acordo com um roteiro narcísico (i.é, a serviço exclusivo do $\mathrm{Eu})$ e porque nele é investido toda a libido para devorar, expulsar ou confundir-se plenamente com a outra pessoa ou ideal.

Como Marraccini (2010) afirma: "Independentemente das características psicopatológicas predominantes, no funcionamento psíquico desses quadros de 'eu em ruína', parece sempre haver a reverberação de um 'trabalho arcaico que não foi cumprido ou completado no início da vida mental. Dessa forma, o desenvolvimento psíquico que foi possível a partir daí, carregou consigo essa marca inicial e seguiu os rastros dessa falha constitutiva. Não podendo esta ser apagada, pode, no entanto, ser alvo da escuta analítica e ser transformada pela relação que se dá na transferência, no interjogo entre paciente e psicanalista'".

Lembrando que a relação transferencial ganha sua potencialidade terapêutica quando possibilita a atualização da relação de dependência sobre a qual se cons- 
titui o psiquismo humano no seu início. Os sujeitos "eu em ruína" haverão de apresentar todas as vicissitudes e dilemas próprios dessa relação de dependência que permanece.

Um risco na teorização entusiasmada de uma nova noção como o Eu em ruínas é constatar sua presença extensa nos diversos acometimentos clínicos com que os pacientes chegam ao consultório do analista. Por isso cabe perguntar: mas, quando e em que condições é possível acontecer o luto que liberta o ego desse objeto idealizado que é vivido como coluna essencial de sustentação? A resposta ou respostas terão de ser encontradas por cada leitor ao longo das diversas situações e facetas em que se configura o Eu em ruínas. É um convite para uma leitura atenta e profícua, pois os diversos autores nos brindam com generosidade a elaboração de uma clínica tal e como se apresenta nos dias de hoje.

\section{Referências}

CinTRA, E. M. de U. Sobre luto e melancolia: uma reflexão sobre o purificar e o destruir. Texto não publicado, cedido pela autora, 2010.

Freud, S. (1917[1915]). Luto e melancolia. In: Edição Standard Brasileira das Obras Psicológicas Completas de Sigmund Freud. Rio de Janeiro: Imago, 1974. v. XIV, p. 271-291.

Laplanche, J.; Pontalis, J-B. Vocabulário da psicanálise. 5. ed. Lisboa: Moraes, 1970.

Quinodoz, J. M. Ler Freud: guia de leitura da obra de S. Freud. Porto Alegre: Artmed, 2007.

\section{ERNesto René SANG}

Psicanalista; Doutor em Psicologia pelo Instituto de Psicologia da Universidade de São

Paulo - IPUSP (São Paulo, SP, Brasil); Membro efetivo da Sociedade Brasileira de Psicanálise de São Paulo - SBPSP (São Paulo, SP, Brasil).

Av. Angélica, 1814/502

01408-010 São Paulo, SP

e-mail: ernestosang@gmail.com 